\title{
Production of sustainable fibre-reinforced concrete incorporating waste chopped metallic film fibres and palm oil fuel ash
}

\author{
HOSSEIN MOHAMMADHOSSEINI* and MAHMOOD MD TAHIR \\ Institute for Smart Infrastructure and Innovative Construction (ISIIC), Construction Research Centre (CRC), \\ Faculty of Civil Engineering, Universiti Teknologi Malaysia (UTM), 81310 Skudai, Johor, Malaysia \\ e-mail: hofa2018@yahoo.com; mhossein@utm.my; mahmoodtahir@utm.my
}

MS received 24 December 2017; revised 7 April 2018; accepted 10 April 2018; published online 10 August 2018

\begin{abstract}
The consumption of waste materials is one of the essential concerns of waste management strategies in many parts of the world. With the advances in concrete technology, the utilisation of waste materials in the sustainable construction has developed increasingly widespread because of technological, economic and ecological advantages. This paper presents the workability and mechanical properties of concrete incorporating waste chopped metallic film (WCMF) fibres and palm oil fuel ash (POFA). Waste plastic results in waste discarding disaster and consequently causes significant harms to the environment. WCMF fibres were prepared by recycling metallic-plastic films used for food packaging. Six concrete mixes containing $0-1.25 \%$ WCMF fibres with a length of $20 \mathrm{~mm}$ were made of ordinary Portland cement (OPC). Further, six concrete mixes with the same fibre content were made, where 20\% POFA substituted OPC. The combination of WCMF fibres and POFA decreased the workability of concrete mixes. The inclusion of WCMF fibres to OPC and POFA concrete mixes decreased the compressive strength. However, at the curing period of 91 days, the POFA-based mixes obtained higher compressive strength values than those of OPC-based mixtures. The positive interaction between WCMF fibres and POFA consequently enhanced the flexural and tensile strengths, impact resistance, thereby increasing energy absorption capacity and ductility of concrete composites. It revealed that WCMF fibres acted as a bridge arrester and improved the load-transfer capacity of the concrete specimens. The study showed that the utilisation of WCMF fibres in the production of sustainable concrete is a beneficial, affordable and feasible solution.
\end{abstract}

Keywords. Sustainability; fibre-reinforced concrete; waste chopped metallic film fibres; palm oil fuel ash; workability; mechanical properties.

\section{Introduction}

Cleaner production involves practices that improve the quality of productions via promoting eco-efficiency and using less natural resources. In the twenty-first century, well-organised management of different types of waste materials is a pressing concern throughout the world. Reducing the solid wastes generated by pre- and postconsumer and the decrease in the utilisation of natural resource are amongst the leading efforts in achieving cleaner and sustainable productions. Through urbanisation and industrialisation, the amount and variety of waste products have raised. From these wastes, different kinds of non-biodegradable wastes will stay in the surroundings for perhaps hundreds or thousands years [1-4]. These nonbiodegradable materials cause waste dumping calamity and therefore create a substantial hazard to the environment. Mohammadhosseini et al [5] and Wattal [6] reported that

*For correspondence well-organised and operational management of various kinds of solid waste are getting more consideration to certify the sustainability in construction industries. In this regard, the use and recycling of solid wastes are the essential matters of waste management approaches all around the world.

In the last century, the performance of concrete in relation to its physical and mechanical properties has been comprehensively studied and investigated owing to the profuse use of this comparatively brittle material in the construction industries. Conventional concrete is a mixture of cement or binders, coarse and fine aggregates and water. It is extensively used in numerous construction industries due to the availability of raw constituents, high stiffness and compressive strength, together with a lower cost $[7,8]$. Due to the low tensile strength and the high rigidity of concrete, it can be considered as a brittle material. Higher tensile strength, impact resistance and energy absorption capacity are therefore needed in different structural and non-structural applications like 
industrial floors, highway paving, bridge decks, etc. Additional components such as short fibres are necessary to enhance these properties of concrete where these requirements are essential [9]. This matter has been conventionally resolved by the addition of small volumes of short and discontinuous fibres into the concrete mixture. Among others, the most popular types of fibres mixed into concrete are glass, steel, polypropylene (PP), waste fibre from pre- and post-consumer and natural fibres [10-13]. Utilisation of post-consumer waste plastics such as polyethene terephthalate (PET) in the production of concrete has revealed possibility towards the sustainable and green construction with a benefit of the harmless alternative of waste plastics disposal [14, 15]. However, the waste metallic plastics are not reprocessed efficiently and have been ignored thus far regarding their potential and sustainable use in the production of green concrete.

In the past 50 years, the plastic production has raised massively globally, and various types and forms of plastics have come to be a vital part of our modern lifestyle. A considerable increase in the consumption of plastic is perceived all over the world, which also raises the generation of plastic-related wastes. Polymer-based plastics are extensively used in more or less all fields, mainly in food packaging, electronics and electrical, automotive, agriculture and other different industries [16]. According to Foti [17], the overall manufacture of plastics is accounted to have raised to 288 million tonnes in 2012, worldwide. Approximately half of these products were one-use consumables, which critically caused the generation of different sorts of plastic wastes.

These plastic wastes are currently an environmental hazard to modern society. Different types of plastics are composed of numerous toxic chemicals, and consequently, plastic wastes pollute the surrounding environment. As plastics are a non-biodegradable material, landfilling solution for disposal of plastics would mean preserving the harmful materials forever. In the last decades, through the growing awareness regarding the environment, lack of landfill area and owing to its ever-growing price, utilisation of wastes has become a desirable alternative solution to discarding [18]. Due to irregular consumption of raw resources, large manufacture quantity of pre- and postconsumer waste materials and environmental pollutions, achieving novel alternative ways are needed for sustainable development. Therefore, the idea of sustainability in the construction industries inspires the utilisation of waste materials to substitute natural resources, for example, cement, aggregates and fibrous materials. This leads to eco-friendly and sustainable construction with lower cost [19].

Metallic-plastic films are made of a polymer coated with a thin sheet of metal, typically aluminium. These films offer the glossy metallic appearance of an aluminium foil at a lower cost and mass. Metallic-plastic films are extensively used for food packaging, particular applications such as insulation and electronics, and also for decorative purposes [20]. Among all, aluminium is the preferred metal applied for coating; however, other metals, for instance nickel or chromium, are also used. This coating will not disappear or fade with time, and it is considerably thinner than a metal foil that could be made, which is about $0.5 \mu \mathrm{m}$. PET and PP are the most common polymeric films that are used for metallisation. The purpose of the film coating is to reduce the penetrability to liquids, air and light [18, 20]. The advantages of using these waste metallic films include the capability of heat sealing, higher toughness, lower density and lower cost as compared with an aluminium foil. Therefore, it offers metallic films some benefits over other types of waste plastics. In this research work, waste metallic-plastic films used for food packaging products such as snack foods, coffee and candy were collected from post-consumer wastes [15, 20].

Utilisation of agricultural waste such as ashes can also help make the construction industries more sustainable and eco-friendly [21]. The consumption of pozzolanic materials in the production of concrete for their benefits is a common practice. Palm oil fuel ash (POFA) is one of the most recent inclusions in the pozzolanic ash category. POFA is obtained from the incineration of palm kernel shells and palm oil husks as fuel in palm oil mills [22]. Malaysia is the second major producer of palm oil crops in the world. According to Ranjbar et al [23], in Malaysia alone, about 4 million tonnes of waste ash was produced in 2010, and this manufacture rate is expected to increase, owing to the growth in the plantation of palm trees. The discarded ash is now considered as a valuable pozzolanic material, as it has satisfactory properties that can be used in the manufacture of durable concrete composites to enhance the durability performance and strength properties [24-26].

Thus far and to the authors' best knowledge, there is limited literature on the utilisation of waste metallic film fibres in the production of concrete, although it has been initiated, and it has been found that these fibrous waste materials have the potential to improve the physical and mechanical properties of concrete composites. Therefore, it is essential to conduct an in-depth study on the behaviour of concrete with a wide range of mix proportions. Since a small quantity of short fibres has been recommended for the enhancement of the strength properties of concrete, it paves the way to use waste chopped metallic film (WCMF) fibres to obtain more strength and impact resistance of concrete containing this fibre. However, according to the author's best knowledge, there is no research work on the combined effects of POFA and WCMF fibres on the performance of concrete composites. Given the accessibility of the waste metallic-plastic films and the pozzolanic nature of POFA, a comprehensive study was conducted to explore the interactive influences of WCMF fibres and POFA on the effective physical and strength properties of sustainable concrete composites. 


\section{Materials and test methods}

\subsection{Materials}

ASTM Type I ordinary Portland cement (OPC) used in this study meets the standards of ASTM C150-07. Raw POFA was collected from a palm oil mill in Malaysia. POFA was dried and sieved to eliminate larger materials and to reduce the carbon content. Ash particles smaller than $150 \mu \mathrm{m}$ were ground in a Los Angeles milling device containing 10 steel bars that were $800 \mathrm{~mm}$ long and $12 \mathrm{~mm}$ in diameter for $2 \mathrm{~h}$ for every $4 \mathrm{~kg}$ of POFA. While moderately spherical, POFA comprises irregular components; a typical electron micrograph of the ash is displayed in figure 1 . The chemical analysis of OPC and POFA was conducted by energydispersive spectrometry, and the results along with the physical properties are given in table 1 . The data show that POFA is reasonably rich in silica content $(62.60 \%)$ as compared with OPC (20.40\%). The amount of $\mathrm{CaO}$, however, is slightly less, i.e., $5.7 \%$. The amount of iron content (5.02\%) is comparable to that of OPC, and according to ASTM C618-15 the ash may be categorised as class C and class $\mathrm{F}$ though, considering the source and type, the ash is neither of class $\mathrm{C}$ nor of class $\mathrm{F}$.

The variation in carbon content of any ash is contingent on the ignition procedure. Loss on ignition (LOI), for

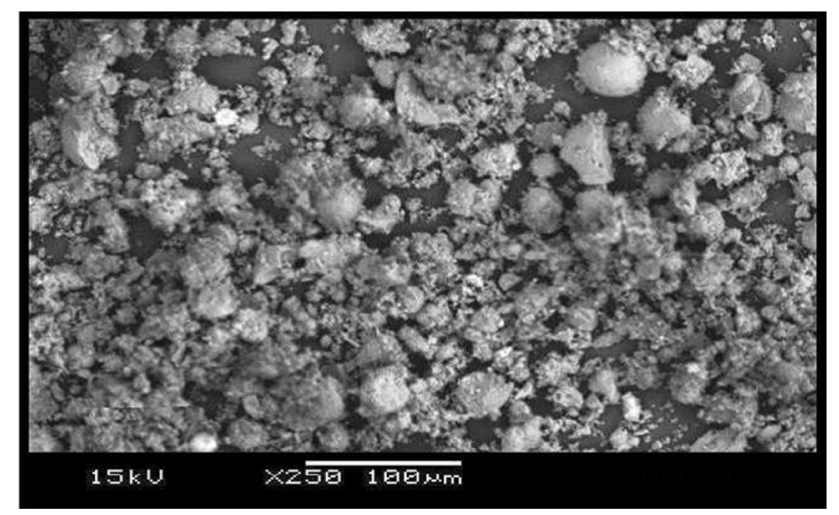

Figure 1. Scanning electron micrograph of POFA. instance, noticed in this study is $6.25 \%$, which is slightly greater than the maximum standard value of $6.0 \%$ specified in ASTM C618-15 for both class F and C. Nevertheless, by a maximum limit of $10 \%$ carbon content for class $\mathrm{N}$, the usage of class $\mathrm{F}$ pozzolan comprising up to $12 \%$ LOI may be permitted if either satisfactory performance record or experimental results are available. It is significant to mention that the 28 days strength activity index of POFA with OPC has been found to be considerably higher (112) than that of the minimum value (75) recommended in a similar standard. While strength activity index is not a direct measure to be deliberated as a value of compressive strength, it is a sign of reactivity with a given cement to estimate the involvement of the mineral admixture to the strength improvement of concrete.

The X-ray diffraction (XRD) pattern of POFA is illustrated in figure 2. The POFA sample was subjected to XRD analysis to check its silica structure. The major mineral that presents a crystalline structure of the respective powders is quartz $\left(\mathrm{SiO}_{2}\right)(\mathrm{Q})$, iron oxide $\left(\mathrm{Fe}_{2} \mathrm{O}_{3}\right)(\mathrm{F})$ and portlandite $\left(\mathrm{Ca}\left(\mathrm{OH}_{2}\right)\right)(\mathrm{P})$. POFA used in this research shows quartz intensity of about 1400 counts. XRD patterns of the POFA showed broad peaks in the range of $20^{\circ}-30^{\circ}$ and centred at $27^{\circ}$; these peaks confirm the amorphous nature of the POFA.

Mining sand with an upper limit of $4.75 \mathrm{~mm}$, a specific gravity of 2.6, fineness modulus of 2.3 and $0.70 \%$ water absorption was employed as the fine aggregates. Coarse aggregate used was crushed granite with a relative specific gravity of $2.7,0.5 \%$ water absorption and maximum size of $10 \mathrm{~mm}$. For mixing and curing purposes, supplied tap water was used. Additionally, to increase the flowability of fresh concrete, a polymer-type superplasticiser at a dosage of $1.0 \%$ by total mass of binders was used. Besides this, waste metallic plastics used for local food packaging were collected and kept in water for $24 \mathrm{~h}$ to remove any impurities. In this study, the PP-type plastic films containing metallisation treatment were used and then shredded into fibres with the length of $20 \mathrm{~mm}$ and a constant $2 \mathrm{~mm}$ width with an aspect ratio $(l / d)$ of 286 , as shown in figure 3 . Aspect ratio is an essential factor that influences the properties and behaviour of the concrete composites. It has been reported that aspect ratio beyond 75 of PP fibres significantly

Table 1. Physical properties and chemical composition of OPC and POFA.

\begin{tabular}{|c|c|c|c|c|c|}
\hline Physical properties & $\mathrm{OPC}$ & POFA & Chemical compositions (\%) & OPC & POFA \\
\hline Specific gravity & 3.15 & 2.42 & $\mathrm{SiO}_{2}$ & 20.40 & 62.60 \\
\hline Blaine fineness $\left(\mathrm{cm}^{2} / \mathrm{g}\right)$ & 3990 & 4930 & $\mathrm{Al}_{2} \mathrm{O}_{3}$ & 5.20 & 4.65 \\
\hline Passing sieve $10 \mu \mathrm{m}(\%)$ & 19 & 33 & $\mathrm{Fe}_{2} \mathrm{O}_{3}$ & 4.19 & 8.12 \\
\hline Soundness $(\mathrm{mm})$ & 1.0 & 2.0 & $\mathrm{CaO}$ & 62.39 & 5.70 \\
\hline \multirow[t]{4}{*}{28 days strength activity index with OPC } & - & 112 & $\mathrm{MgO}$ & 1.55 & 3.52 \\
\hline & & & $\mathrm{K}_{2} \mathrm{O}$ & 0.005 & 9.05 \\
\hline & & & $\mathrm{SO}_{3}$ & 2.11 & 1.16 \\
\hline & & & LOI & 2.36 & 6.25 \\
\hline
\end{tabular}




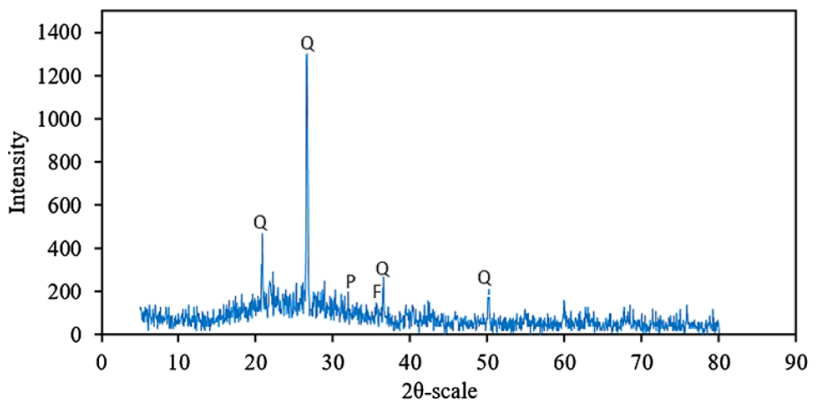

Figure 2. X-ray diffraction pattern of POFA.

increases the ultimate strength, mainly splitting and flexural strengths, of concrete $[13,20]$. However, PP fibres with aspect ratio in the range $40-1600$ have been used as reported in the literature [27-30]. The fibres used in this study with an aspect ratio of 286 are in this range. Some of the characteristics of used waste metallic-plastic fibres are presented in table 2 .

\subsection{Mix proportion and sample preparation}

Different mix proportions of OPC and POFA-based concrete composites are given in table 3. Altogether, 12 mixes with different fibre volume fractions were prepared, of which one batch was made without any fibre content, and POFA was assumed as the control mix. Amongst the 12 batches, six of them, namely group OPC (B1-B6), were OPC based with WCMF fibres content of $0,0.25,0.50$, $0.75,1.0$ and $1.25 \%$. The other six mixes, which are called as group POFA (B7-B12), were prepared by substituting $20 \%$ POFA in OPC for similar fibre content.

\subsection{Testing methods}

The fresh concrete mixtures were investigated for their slump test following BS EN 12350-2: 2009 and VeBe test following BS EN 12350-3: 2009. Cube specimens of size
Table 2. Engineering properties of WCMF fibres.

\begin{tabular}{lc}
\hline Property & Values \\
\hline Resin category & Polypropylene \\
Plastic type & LDPE \\
Thickness $(\mathrm{mm})$ & 0.07 \\
Size $(W \times L)(\mathrm{mm})$ & $2 \times 20$ \\
Density range $\left(\mathrm{kg} / \mathrm{m}^{3}\right)$ & $0.915-0.945$ \\
Tensile strength $(\mathrm{MPa}$ & 400 \\
Elongation $(\%)$ & $8-10$ \\
Reaction with water & Hydrophobic \\
\hline
\end{tabular}

$100 \mathrm{~mm}$ were used for compressive strength test in conformity with BS EN 12390-3: 2009. In this study, the tensile strength test following ASTM C496-11 was conducted using cylindrical samples of size $100 \mathrm{~mm} \times 200 \mathrm{~mm}$ at the curing periods of 7, 28 and 91 days. The flexural strength test (BS EN 12390-5: 2009) was also conducted using prism samples with sizes of $100 \mathrm{~mm} \times 100 \mathrm{~mm} \times 500 \mathrm{~mm}$ at the same curing ages. Ultrasonic pulse velocity (UPV) test was carried out through a pulse velocity measuring apparatus. The UPV test was piloted on the $100 \mathrm{~mm}$ concrete cube samples before the compressive strength test following ASTM C597-09 (figure 4).

The impact test of concrete disk samples was conducted as per ACI committee 544 . A hammer of $4.45 \mathrm{~kg}$ mass was frequently released from a height of $457 \mathrm{~mm}$ on a stainlesssteel ball having $63.5 \mathrm{~mm}$ diameter placed at the centre of the top surface of the concrete disks. For each batch of concrete, three disks having $150 \mathrm{~mm}$ diameter and $64 \mathrm{~mm}$ thickness were made and used for the drop-weight impact resistance test.

\section{Results and discussion}

\subsection{Workability}

Slump and VeBe time tests were carried out to evaluate the effects of POFA and WCMF fibres on the consistency of

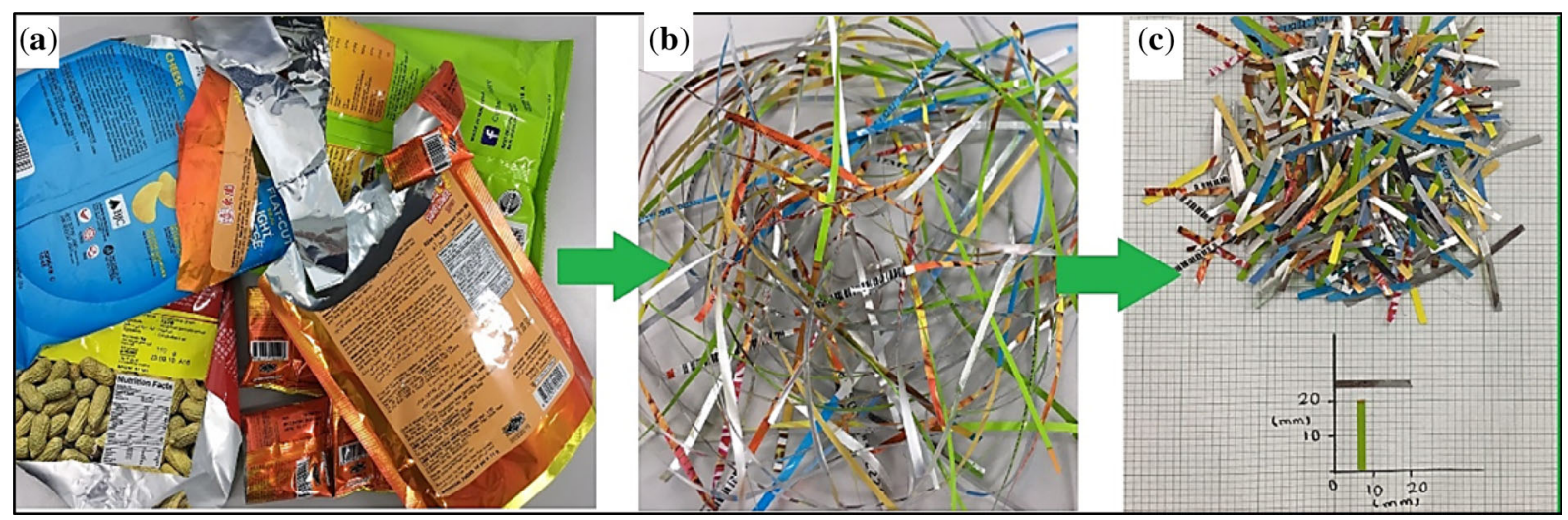

Figure 3. (a) Waste metallic-plastic films, (b) fabricated WCMF fibres and (c) WCMF fibres used in this study. 
Table 3. Mix proportions of the concrete composites.

\begin{tabular}{|c|c|c|c|c|c|c|}
\hline Mix & Cement $\left(\mathrm{kg} / \mathrm{m}^{3}\right)$ & POFA $\left(\mathrm{kg} / \mathrm{m}^{3}\right)$ & Water $\left(\mathrm{kg} / \mathrm{m}^{3}\right)$ & Fine aggregate $\left(\mathrm{kg} / \mathrm{m}^{3}\right)$ & Coarse aggregate $\left(\mathrm{kg} / \mathrm{m}^{3}\right)$ & $V_{\mathrm{f}}(\%)$ \\
\hline B1 & 445 & - & 215 & 830 & 860 & 0.0 \\
\hline B2 & 445 & - & 215 & 830 & 860 & 0.25 \\
\hline B3 & 445 & - & 215 & 830 & 860 & 0.50 \\
\hline B4 & 445 & - & 215 & 830 & 860 & 0.75 \\
\hline B5 & 445 & - & 215 & 830 & 860 & 1.0 \\
\hline B6 & 445 & - & 215 & 830 & 860 & 1.25 \\
\hline B7 & 356 & 89 & 215 & 830 & 860 & 0.0 \\
\hline B8 & 356 & 89 & 215 & 830 & 860 & 0.25 \\
\hline B9 & 356 & 89 & 215 & 830 & 860 & 0.50 \\
\hline B10 & 356 & 89 & 215 & 830 & 860 & 0.75 \\
\hline B11 & 356 & 89 & 215 & 830 & 860 & 1.0 \\
\hline B12 & 356 & 89 & 215 & 830 & 860 & 1.25 \\
\hline
\end{tabular}

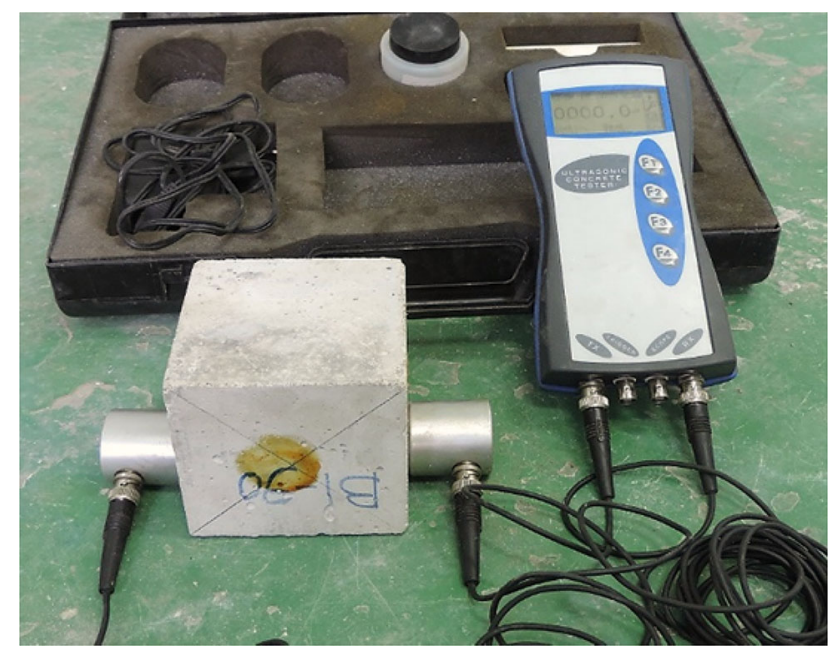

Figure 4. The UPV test apparatus.

concrete composites and the results are shown in figure 5a and $b$. It was observed that the workability of fresh mixtures was significantly influenced by WCMF fibres and POFA. It was found that the presence of WCMF fibre in the mixtures caused a reduction in the slump values of fresh mixtures. The addition of WCMF fibres affects the viscosity of the matrix. The inclusion of fibres at higher dosage also interrupts the consistency of the mixture, which is related to the balling effect of concrete components and WCMF fibres.

As illustrated in figure 5a, the slump value of the control mixture (B1) was recorded as $190 \mathrm{~mm}$. By the addition of WCMF fibre at a dosage of $0.25 \%, 0.5 \%, 0.75 \%, 1 \%$ and $1.25 \%$, the slump values reduced to $120,80,65,40$ and $30 \mathrm{~mm}$, respectively. Furthermore, the addition of POFA into the mixtures makes the matrix denser by filling up the micro-pores in the mixture, as stated by Zeyad et al [31]. Consequently, it caused a stiffer mixture with a corresponding decrease in the flowability of the matrix. From the experimental findings, it is evident that with the addition of $20 \%$ POFA into the mixture, the slump values reduce to $170 \mathrm{~mm}$ and $\mathrm{VeBe}$ time increases to $16 \mathrm{~s}$ compared with $190 \mathrm{~mm}$ and $15.3 \mathrm{~s}$, respectively, for OPC control mixture (B1), as shown in figure 5b. Increased fibre volume fractions in POFA-based mixtures also contributed to the reduction in workability of concrete composites. For example, the slump values of $110,50,40,35$ and $20 \mathrm{~mm}$
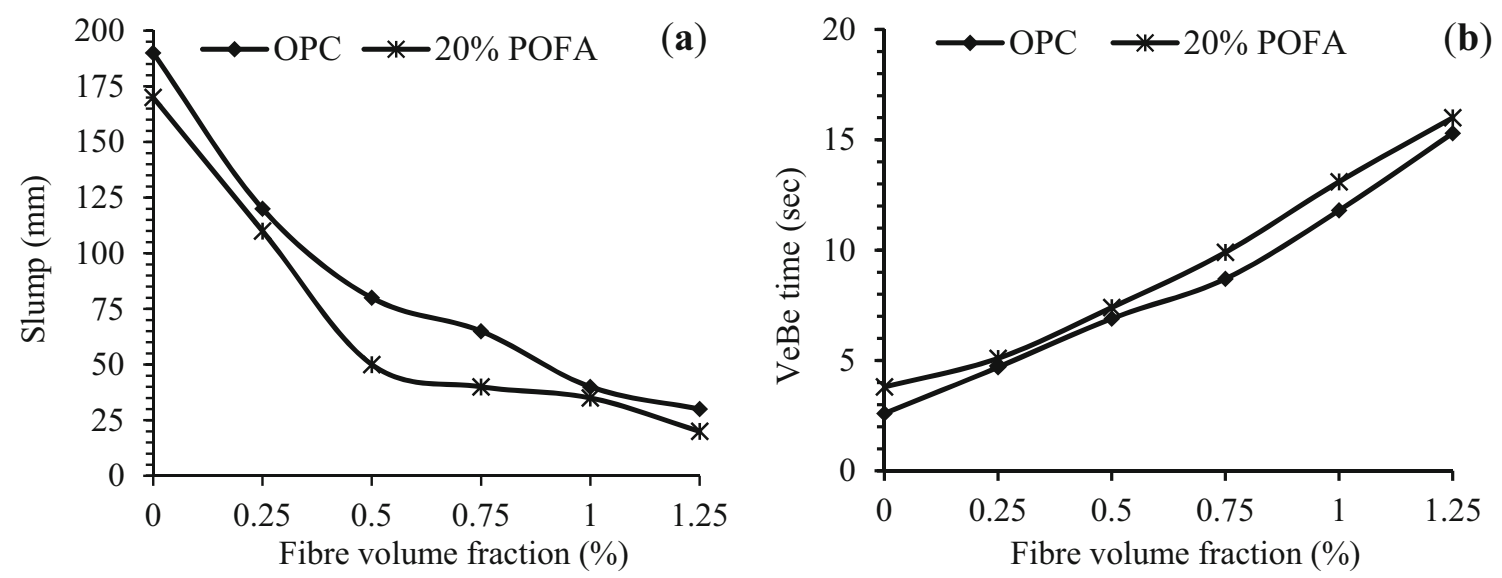

Figure 5. Effects of WCMF fibres on (a) slump values and (b) VeBe times of various concrete mixes. 

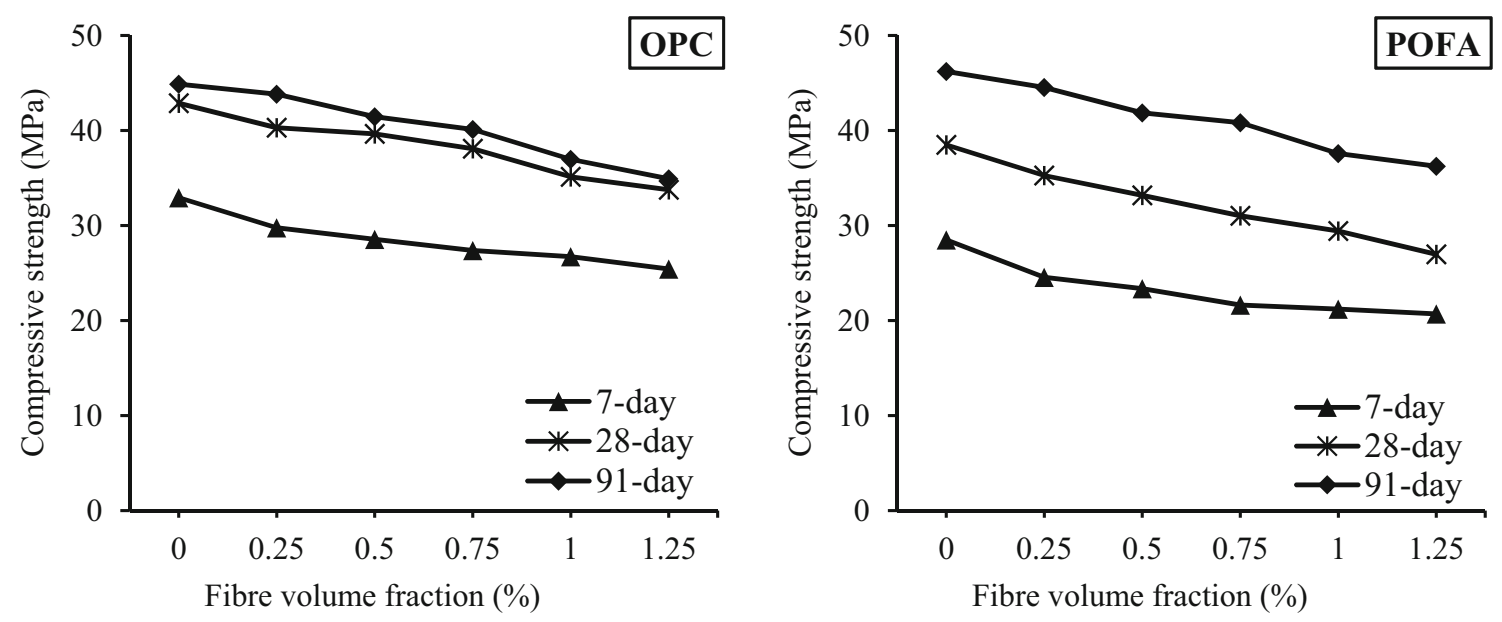

Figure 6. Variation in the compressive strength of concrete mixes reinforced with WCMF fibres.

were recorded for the corresponding fibre contents. For a given fibre volume fraction, the addition of a constant amount of POFA caused higher VeBe times as well.

\subsection{Compressive strength}

The experimental results reveal that the cube compressive strength of all concrete mixtures reduces by raising fibre dosage. Figure 6 demonstrates the experimental results of the compressive strength of concrete mixtures incorporating WCMF fibres at different curing periods. The inclusion of WCMF fibres at a dosage of $0.25 \%, 0.5 \%, 0.75 \%, 1 \%$ and $1.25 \%$ reduced the cube compressive strength by $6.1 \%$, $7.53 \%, 11.14 \%, 18 \%$ and $21.25 \%$, respectively, as compared with that of control mixture (B1). In concrete mixtures with $20 \%$ POFA, further decreases in compressive strength of $13.5 \%$ at 7 days and $10.2 \%$ at 28 days curing were observed related to that of the OPC-based concrete mix. However, at the curing period of 91 days, POFAbased fibrous concrete mixtures attained compressive strength values higher than that of OPC-based mixtures. It is apparent that for long curing periods, the increase in strength of POFA mixtures was significant. It is well known that the POFA improved the performance of concrete mix by the pozzolanic action and creation of additional calcium silicate hydrate (C-S-H) gel [32].

This excellent distribution and creation of the additional C-S-H gel is owing to the utilisation of calcium hydroxide during the hydration process by the pozzolanic activity of POFA and causes higher strength of mixes, particularly at the ultimate ages. It is understood that the addition of POFA improves and densifies the matrix through its pozzolanic nature and decreases the amount of $\mathrm{Ca}(\mathrm{OH})_{2}$ in OPC [22]. Furthermore, as illustrated in figure 7, the

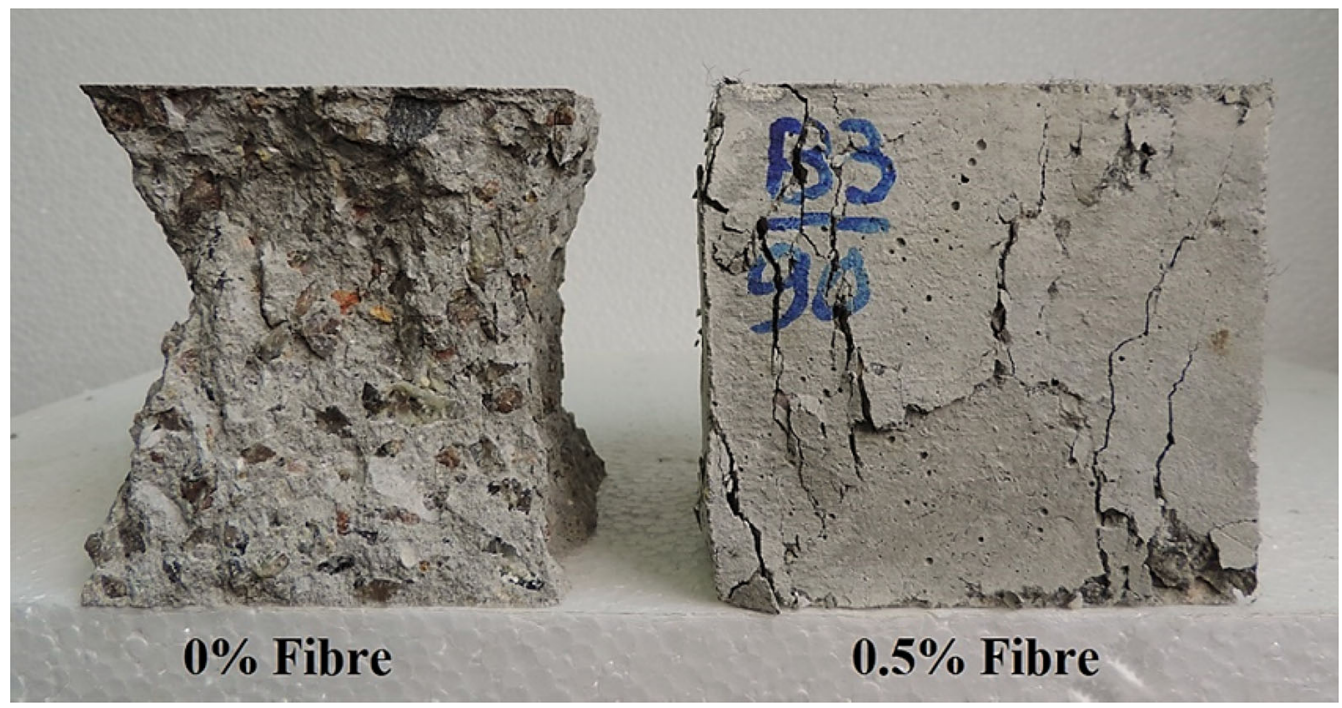

Figure 7. Comparison of failure modes of concrete specimens with and without WCMF fibres under compressive load. 
addition of WCMF fibres in the concrete mixtures considerably improves the brittleness of concrete and prevents the sudden failure of the specimens under compression loads. This phenomenon is attributed to the bridging action of WCMF fibres, which hold the concrete constituents up to the end of the loading process.

\subsection{Splitting tensile strength}

Figure 8 displays the variation in the results of tensile strength vs. WCMF fibre volume fractions. It can be seen that with the addition of WCMF fibres and increase in dosage, the tensile strength values of concrete mixtures are considerably higher than those of the control mix. Although splitting happened across the specimen and continued, the fibres linked the split section of the specimen. Consequently, this gradually sustained the tensile stresses and delayed the failure of concrete specimens. The resistance against the indirect tension improves the strain capability of the specimens, and therefore results in higher splitting tensile strength of those specimens reinforced with short fibres than those of plain concrete mixture [33].

Figure 8 further reveals that the incorporation of WCMF fibres and POFA contributes to the improvement of tensile strength. The 91-day tensile strength values of OPC-based concrete mixes increased by $12.0 \%, 18.9 \%, 16.9 \%, 13.4 \%$ and $8.0 \%$ for the fibre dosages of $0.25 \%, 0.5 \%, 0.75 \%, 1 \%$ and $1.25 \%$, respectively, compared with that of control concrete mix. At the same curing period, the inclusion of POFA to the fibrous concrete enhanced the strength values by $13.1 \%, 22.3 \%, 18.0 \%, 14.9 \%$ and $11.4 \%$ for the corresponding fibres content, compared with the control mixture (B1). The improvement in the tensile strength could be due to the greater contact surface area amongst WCMF fibres and the binder paste. It could be attributed to the higher pozzolanic hydration products, which is in line owing to the good pozzolanic nature of POFA at the ultimate ages [34].

\subsection{Flexural strength}

Figure 9 demonstrates the obtained results of flexural strength test. The results indicate that the flexural strength of mixtures that incorporate WCMF fibres is significantly higher than that of the control mix. Flexural strength values varying in the range $3.0-3.99,3.84-5.13$ and 4.90-5.95 MPa were recorded for all concrete mixtures with the fibre dosages increasing from $0 \%$ to $1.25 \%$, at the curing periods of 7, 28 and 91 days, respectively. A comparable tendency like that of splitting tensile was also noted for the concrete flexural strength values. For example, for the POFA-based mixture comprising $0.5 \%$ WCMF fibres at the age of 91 days, the value of $5.95 \mathrm{MPa}$ was recorded, which was the highest amongst all and $21.4 \%$ higher than that of the control mixture. The said enhancement was attributed to the higher pozzolanic action of POFA and formation of extra C-S-H gels, particularly at ultimate ages, which enhance the strength values of concrete mixtures.

The fibres interconnect the micro-cracks in the tension region of the concrete prisms, and therefore improve the flexural strength. WCMF fibres act as a cracks arrester and grip the cracks propagation over their extending; consequently, the fibres afford a higher energy absorption capacity for the cracks zone contiguous to the tip of the cracks. Nevertheless, additional raises in fibre content to more than $0.75 \%$ cause a reduction of flexural strength, but the obtained values are yet higher than that of control mixture. This reduction in flexural strength can be owing to the lower workability and existence of pores at a high fibres dosage and also an uneven distribution of fibres.

\subsection{Impact resistance}

In this work, the impact resistance of different concrete mixtures incorporating WCMF fibres is examined through a
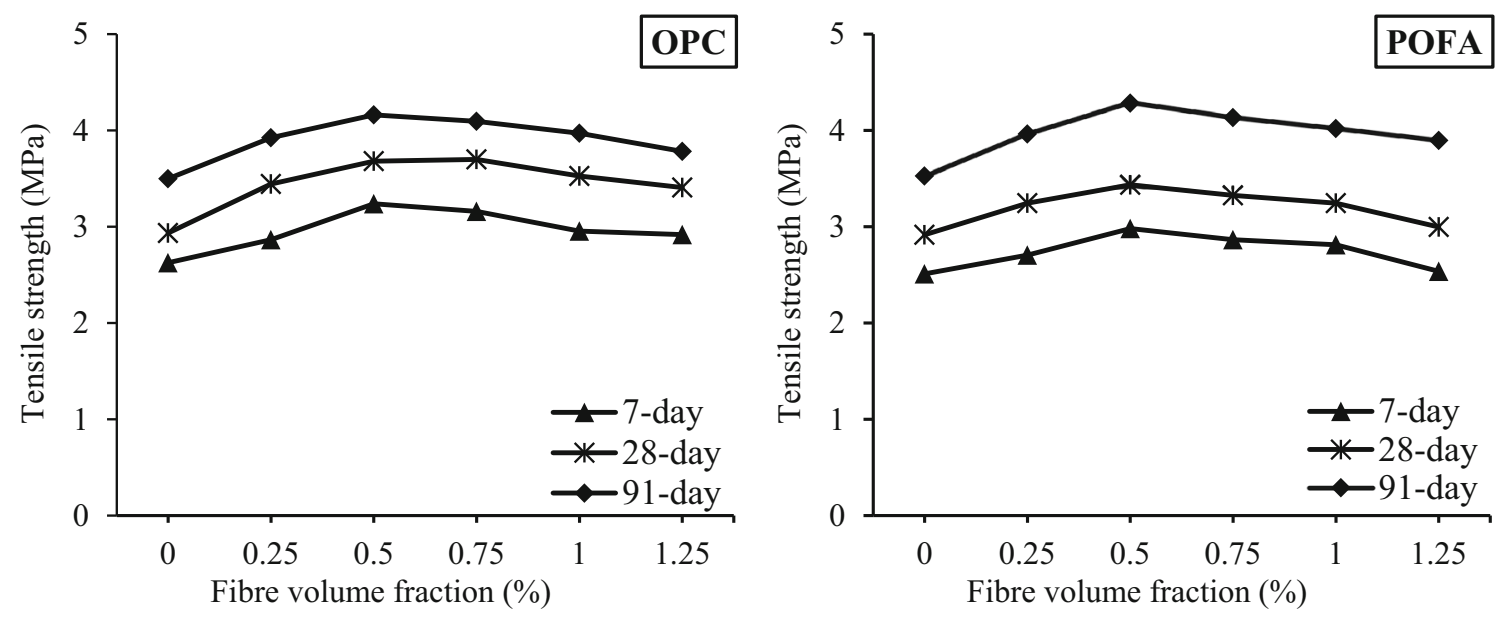

Figure 8. Effects of WCMF fibres on the tensile strength values of concrete composites. 

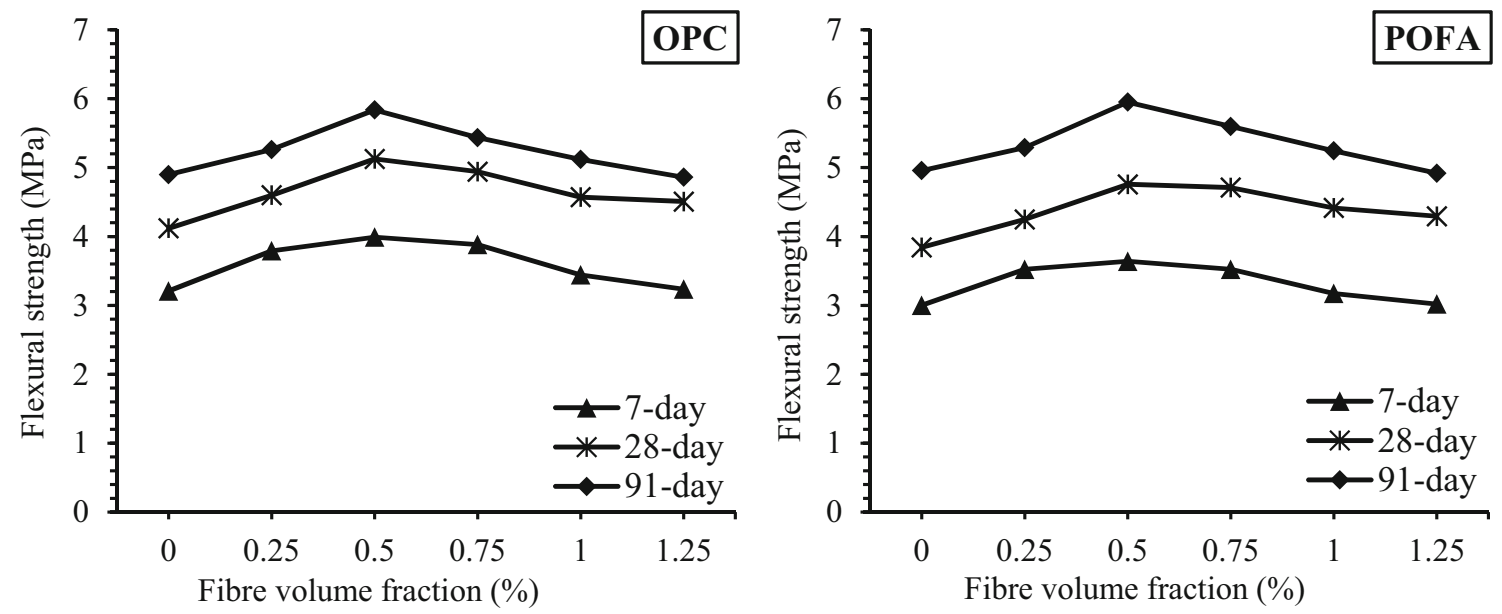

Figure 9. Effects of WCMF fibres on the flexural strength values of concrete composites.
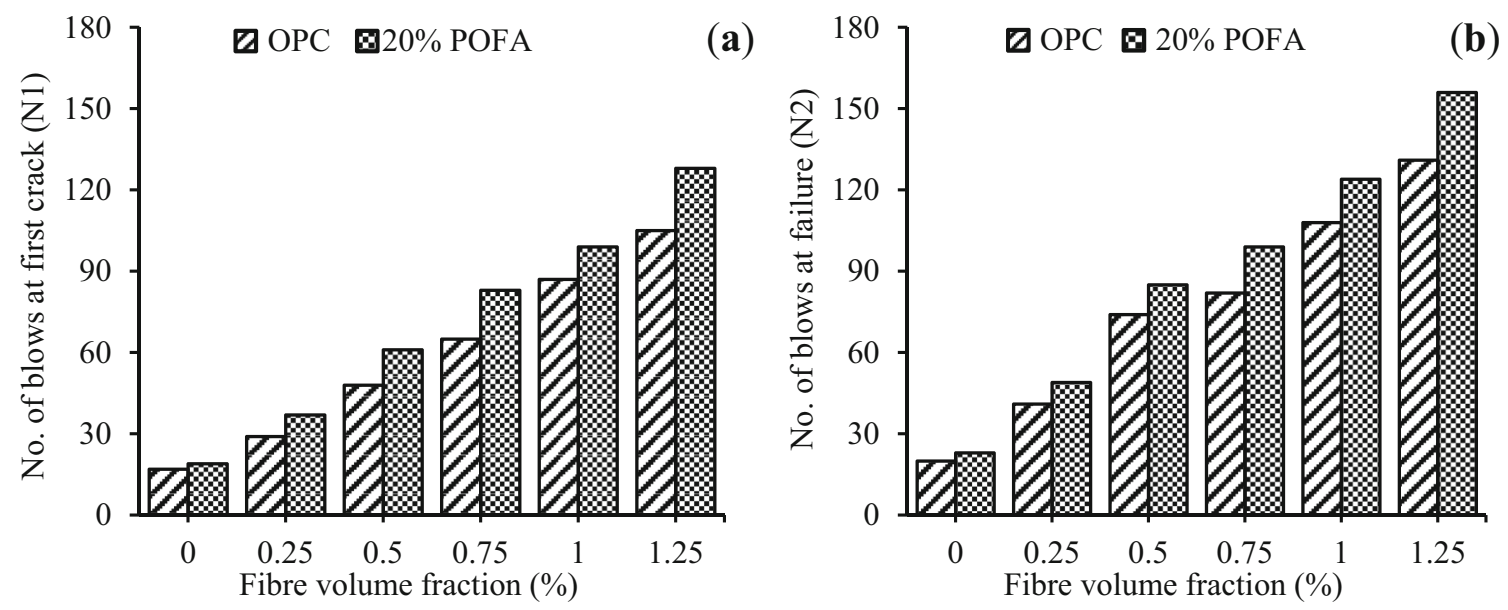

Figure 10. Effects of WCMF fibres on the impact resistance of concrete composites at (a) first crack and (b) failure.

number of blows necessary to obtain the first crack (N1) and failure (N2) of the concrete disk specimens. According to the obtained results, adding WCMF fibres enhanced the initial and ultimate crack impact resistance of the concrete composites, and further development was noted for the impact resistance at the ultimate crack, as associated with the impact resistance at the initial crack. As shown in figure 10a, reinforcement of plain concrete mixtures with WCMF fibres of $0.25 \%, 0.5 \%, 0.75 \%, 1 \%$ and $1.25 \%$ improved the impact resistance of disk specimens by $70.6 \%, 182.3 \%, 282.4 \%, 411.8 \%$ and $517.6 \%$, respectively, at the initial crack. Furthermore, the impact resistance at ultimate crack raised by $105 \%, 270 \%, 310 \%, 440 \%$ and $555 \%$ for the concrete mixtures containing corresponding fibre volume fractions.

The obtained values of the impact resistance at the initial and ultimate crack for POFA-based concrete composites show a significant improvement compared with those of OPC-based concrete mixtures. Figure $10 \mathrm{~b}$ reveals that the combination of WCMF fibres and POFA significantly increased the impact resistance of concrete. For instance, by the addition of WCMF fibres at the dosage of $0.25 \%$, $0.5 \%, 0.75 \%, 1 \%$ and $1.25 \%$, the first crack impact resistance increased by $94.7 \%, 221 \%, 336.8 \%, 421.1 \%$ and $573.7 \%$, respectively, as compared with that of plain POFA-based mixture (B6). Furthermore, the ultimate crack impact resistances increased by $113 \%, 269.6 \%, 330.4 \%$, $439.1 \%$ and $578.3 \%$ for the concrete mixtures containing corresponding fibre volume fractions, respectively, which are considerably higher than those of OPC-based fibrous mixtures. As mentioned earlier, the pozzolanic behaviour of POFA modified the microstructure of the concrete mixtures and resulted in higher strength and energy absorption, particularly at the ultimate ages [13]. Figure 11 shows the concrete specimens used in impact resistance test before and after failure. It can be seen the by addition and a further increase in the fibre volume fractions; more cracks appear on the surface of the specimens and the concrete changes from a brittle material to a ductile with a higher energy absorption capacity. 

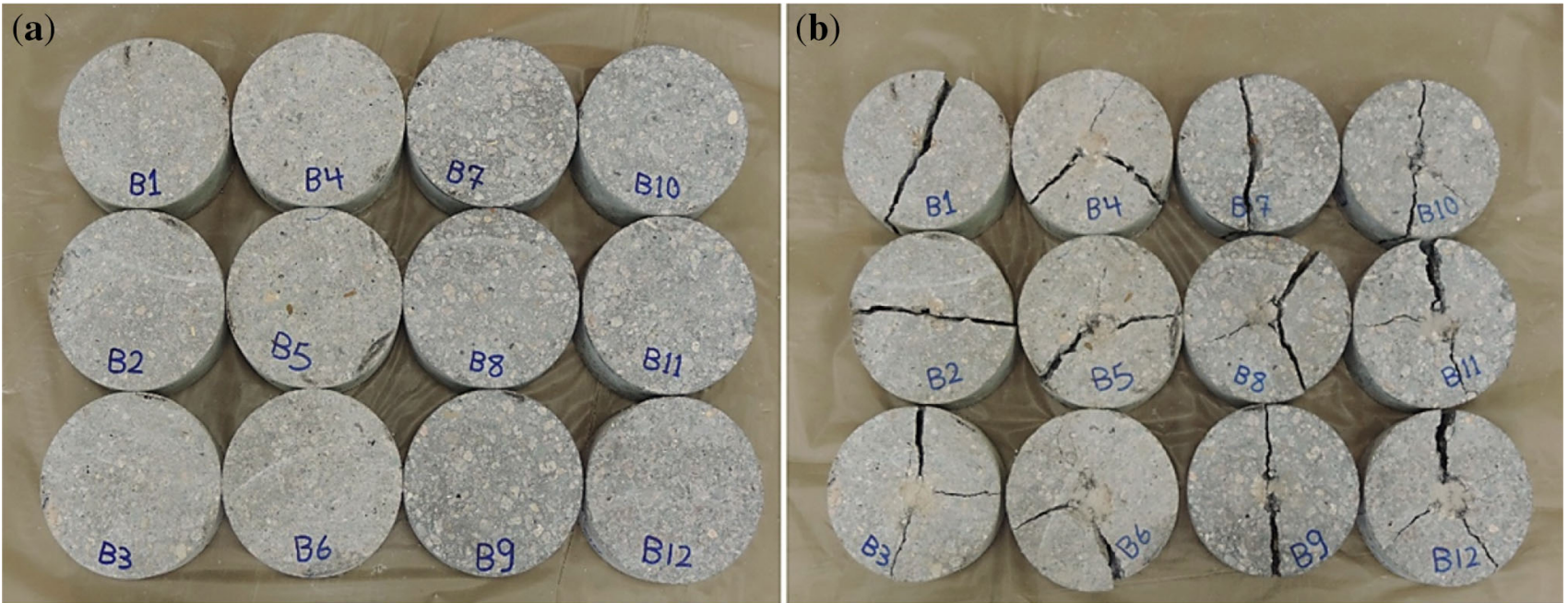

Figure 11. Concrete specimens used for impact resistance test: (a) before loading and (b) cracks formation after drop weight test.
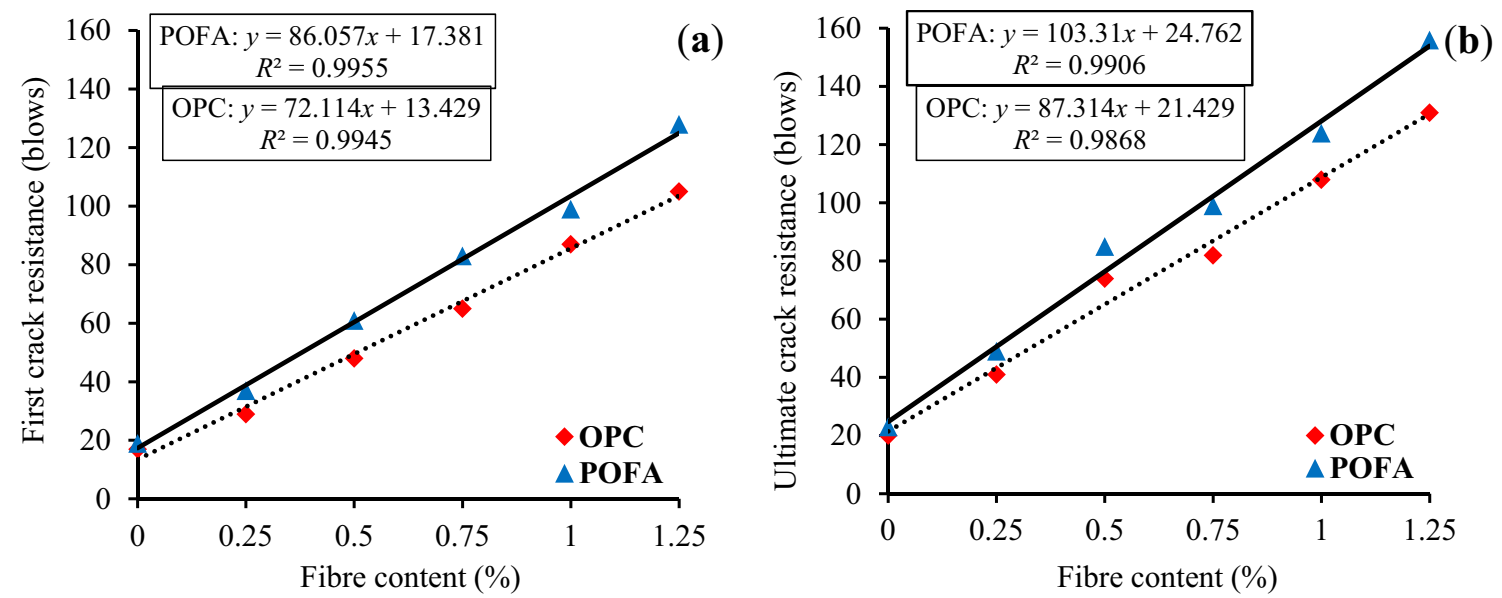

Figure 12. Regression for the impact resistance of (a) first crack and (b) ultimate crack.

Based on the obtained results, the initial and ultimate crack impact resistance of the concrete specimens reinforced by WCMF fibres is correlated to the fibre volume fractions and depicted in figure 12. Apparently a good correlation between the impact resistance and increase of the WCMF fibre volume fractions can be seen. To compare the experimental findings, a linear regression analysis was used to develop empirical relations as shown in Eqs. (1)(4). Figure 12a illustrates the correlation between initial crack impact resistance and fibre volume fractions of different mixes. Equation (1) displays the significant relation between initial crack impact resistance and fibre volume fractions, with $R^{2}$ of 0.994 for OPC-based concrete mixtures. Equation (2) reveals the excellent correlation with $R^{2}$ of 0.995 between initial crack impact resistance and fibre volume fractions for POFA-based concrete mixtures, indicating good confidence for this relationship.
Figure $12 \mathrm{~b}$ demonstrates the correlation between ultimate crack impact resistance and fibre volume fractions. Equations (3) and (4) present the good relations between ultimate crack impact resistance and fibre volume fractions, with $R^{2}$ of 0.986 and 0.99 for OPC and POFA-based concrete mixes, respectively:

$$
\begin{array}{ll}
\text { A: } \mathrm{FC}=72.114 V_{\mathrm{f}}+13.429, & R^{2}=0.9945 \\
\text { B: } \mathrm{FC}=86.057 V_{\mathrm{f}}+17.381, & R^{2}=0.9955 \\
\text { A: } \mathrm{UC}=87.314 V_{\mathrm{f}}+21.429, & R^{2}=0.9868 \\
\text { B: } \mathrm{UC}=103.31 V_{\mathrm{f}}+24.762, & R^{2}=0.9906
\end{array}
$$

where A is OPC-based mixtures, B is POFA-based mixtures, FC is the impact resistance at first crack, UC is the 

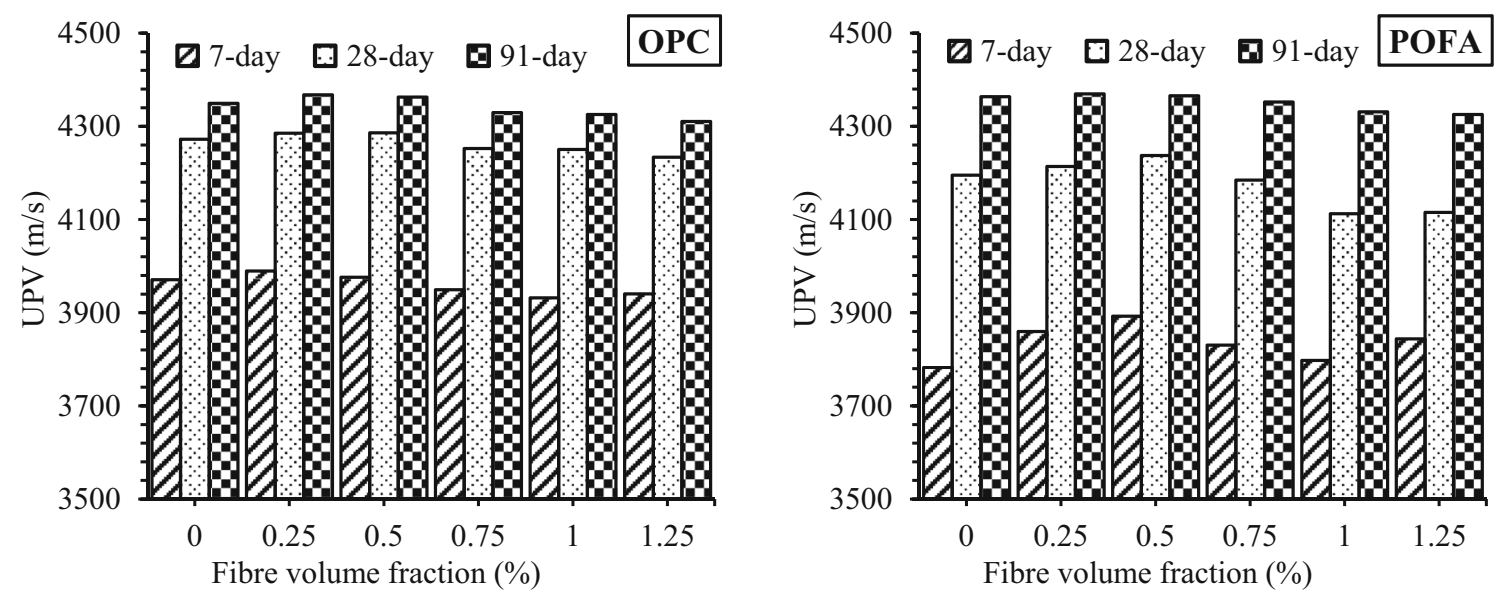

Figure 13. The effects of WCMF fibres on UPV values of concrete mixtures.

impact resistance at the ultimate crack and $V_{\mathrm{f}}$ is the fibre volume fraction.

\subsection{Ultrasonic pulse velocity}

In this study, a non-destructive test of UPV that involves measurement of the time of travel of electronically generated mechanical pulses through the concrete specimens was used. Figure 13 demonstrates the variation in the obtained UPV values of concrete mixes comprising POFA and WCMF fibres. It was found that the WCMF fibres produced no remarkable influence on the UPV at early ages. However, along with the time the UPV values improved. The values of 4272 and $4349 \mathrm{~m} / \mathrm{s}$ were obtained for control concrete mixture at the ages of 28 and 91 days, respectively, which are categorised as a good quality concrete, as stated by Neville and Brooks [35].

The addition of WCMF fibres up to a specific volume fraction improved the UPV values. For instance, at 91 days, the values of 4367 and $4363 \mathrm{~m} / \mathrm{s}$ were recorded for mixtures containing $0.25 \%$ and $0.5 \%$ WCMF fibres, respectively, which were higher than that of the control mixture. Nonetheless, the UPV values were significantly reduced by an increase in dosage of fibre contents, as expected. It is known that the reduction in UPV values is owing to the micropores and cracks, which decrease the uniformity of the matrix for a high dosage of fibres. Furthermore, the addition of POFA in concrete composites containing WCMF fibres significantly increased the UPV values, particularly at the ultimate ages. Values higher than $4300 \mathrm{~m} / \mathrm{s}$ were recorded for POFA-based concrete mixtures at the age of 91 days. This was expected owing to the high pozzolanic activity of POFA particularly at ultimate ages and growth of extra C-S-H gels, which makes the matrix denser with lower porosity $[21,36]$.

Figure 14 displays the relationship between the obtained values of UPV and compressive strength for various

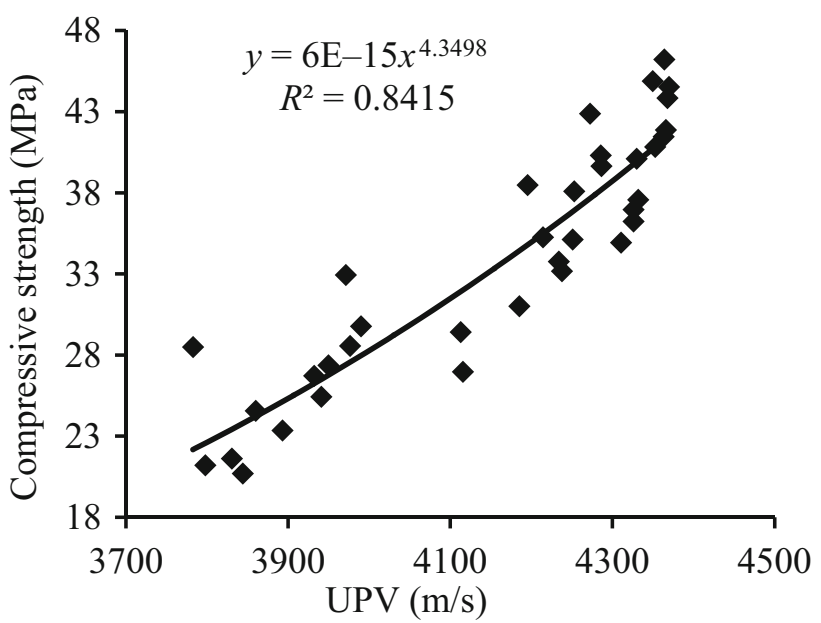

Figure 14. Relationships between compressive strength and UPV.

mixtures containing POFA and WCMF fibres. Obviously a good correlation can be seen between the UPV and compressive strength values at all ages. To compare the experimental findings, a power regression method was used as shown in Eq. (5), with an $R^{2}$ value of 0.84 , indicating good confidence for this correlation:

$$
f_{\text {cu }}=6 \mathrm{E}-15 V^{4.3498}, \quad R^{2}=0.8415
$$

where $f_{\text {cu }}$ is the compressive strength (MPa) and $V$ is the UPV $(\mathrm{m} / \mathrm{s})$.

\section{Conclusions}

This study focuses on the influence of waste metallicplastic film (WCMF) fibres and POFA on the effective physical and mechanical properties of concrete composites. The environmental benefit of efficiently using these waste 
materials is the primary incentive for this study. From the observations made and experimental findings, the following conclusions can be drawn:

- In the fresh concrete mixtures, the addition of WCMF fibres resulted in lower workability. The higher the WCMF fibre dosage, the lesser the slump values and the higher the VeBe times.

- The cube compressive strength reduced with the raise in fibre volume fractions. The development in the strength of POFA-based mixtures at early ages was almost similar to that of OPC concrete mixes. At 91 days of curing, the compressive strength of POFAbased concrete mixtures exceeded the values of OPC concrete mixtures.

- Contrary to lower improvements in compressive strength, notable developments in the tensile and flexural strengths of the concrete composites were observed. In all curing periods, the mixtures comprising WCMF fibres and POFA achieved superior enhancement of flexural and tensile strengths owing to firm fibre-cement matrix boundary and densification of the matrix. The 91-day tensile strength of concrete mix comprising $0.5 \%$ fibre improved by $18.85 \%$ for OPC mixture and $22.29 \%$ for the POFA-based concrete mixture as compared with the control mixture. The flexural strength values were likewise increased by $19.18 \%$ and $21.43 \%$ for the corresponding situations.

- The combination of WCMF fibres and POFA enhanced the ductility of concrete composites and energy absorption capacity, and led to a uniform crack distribution.

- The inclusion of WCMF fibres and increasing fibre volume fractions significantly enhanced the impact resistance of concrete composites. The maximum rate of increasing impact resistance was attained in the concrete specimens reinforced with WCMF fibre at a volume fraction of $1.25 \%$. However, the highest values were detected in the POFA-based concrete mixture.

- The UPV values of 3700-4400 m/s, which characterise a good quality concrete, were obtained for all mixes containing WCMF fibres and POFA.

- The findings of this study indicate that the production of sustainable concrete composites comprising WCMF fibres and POFA can be developed with adequate physical and mechanical properties in the construction of low-cost housing.

- The results obtained and the observation made in this study indicate that concrete incorporating WCMF fibres and POFA can be used with satisfactory engineering properties in the construction of building slabs, road pavements and other structural and nonstructural applications. Hence, large-scale application of WCMF fibres together with a study of its performance behaviour in reinforced concrete members has been put forward as a recommendation for a future investigation.

\section{Acknowledgements}

The authors wish thank for the help and co-operation received from the technical staff of Structure and Materials Laboratory of the Universiti Teknologi Malaysia (UTM) in conducting the experimental work. Also, the first author acknowledges the research grant funded by Universiti Teknologi Malaysia (UTM) under the postdoctoral fellowship scheme (Vot No. Q.J130000.21A2.04E11).

\section{References}

[1] Sharma R and Bansal P P 2016 Use of different forms of waste plastic in concrete-a review. Journal of Cleaner Production 112: 473-482

[2] Siddique R, Khatib J and Kaur I 2008 Use of recycled plastic in concrete: a review. Waste Management 28(10): 1835-1852

[3] Švajlenka J, Kozlovská M and Spišáková M 2017 The benefits of modern method of construction based on wood in the context of sustainability. International Journal of Environmental Science and Technology 14(8): 1591-1602

[4] Mohammadhosseini H, Awal A S M A and Ehsan A H 2015 Influence of palm oil fuel ash on fresh and mechanical properties of self-compacting concrete. Sadhana 40(6): 1989-1999

[5] Mohammadhosseini H, Tahir M M, Sam A R M, Lim N H A $S$ and Samadi M 2018 Enhanced performance for aggressive environments of green concrete composites reinforced with waste carpet fibers and palm oil fuel ash. Journal of Cleaner Production 185: 252-265

[6] Wattal P K 2013 Indian programme on radioactive waste management. Sadhana 38(5): 849-857

[7] Mosavi S M and Nik A S 2015 Strengthening of steel-concrete composite girders using carbon fibre reinforced polymer (CFRP) plates. Sadhana 40(1): 249-261

[8] Muhammad B, Ismail M, Bhutta M A R and Abdul-Majid Z 2012 Influence of non-hydrocarbon substances on the compressive strength of natural rubber latex-modified concrete. Construction and Building Materials 27(1): 241-246

[9] Yardimci M Y, Baradan B and Taşdemir M A 2014 Effect of fine to coarse aggregate ratio on the rheology and fracture energy of steel fibre reinforced self-compacting concretes. Sadhana 39(6): 1447-1469

[10] Alhozaimy A M, Soroushian P and Mirza F 1996 Mechanical properties of polypropylene fiber reinforced concrete and the effects of pozzolanic materials. Cement and Concrete Composites 18(2): 85-92

[11] Sun Z and Xu Q 2009 Microscopic, physical and mechanical analysis of polypropylene fiber reinforced concrete. Materials Science and Engineering: A 527(1): 198-204

[12] Yap S P, Alengaram U J and Jumaat M Z 2013 Enhancement of mechanical properties in polypropylene- and nylon-fibrereinforced oil palm shell concrete. Materials \& Design 49: 1034-1041

[13] Mohammadhosseini H, Awal A S M A and Yatim J B M 2017 The impact resistance and mechanical properties of concrete reinforced with waste polypropylene carpet fibres. Construction and Building Materials 143: 147-157 
[14] Sadrmomtazi A, Dolati-Milehsara S, Lotfi-Omran O and Sadeghi-Nik A 2016 The combined effects of waste Polyethylene Terephthalate (PET) particles and pozzolanic materials on the properties of self-compacting concrete. Journal of Cleaner Production 112: 2363-2373

[15] Mohammadhosseini H, Tahir M M and Sam A R M 2018 The feasibility of improving impact resistance and strength properties of sustainable concrete composites by adding waste metalized plastic fibres. Construction and Building Materials 169: 223-236

[16] Gu L and Ozbakkaloglu T 2016 Use of recycled plastics in concrete: a critical review. Waste Management 51: 19-42

[17] Foti D 2013 Use of recycled waste pet bottles fibers for the reinforcement of concrete. Composite Structures 96: 396-404

[18] Bhogayata A C and Nakum A 2015 Strength characteristics of concrete containing post-consumer metallic plastic waste. International Journal of Research in Engineering and Technology 4(9): 430-434

[19] Stonys R, Kuznetsov D, Krasnikovs A, Škamat J, Baltakys K, Antonovič V and Černašèjus O 2016 Reuse of ultrafine mineral wool production waste in the manufacture of refractory concrete. Journal of Environmental Management 176: $149-156$

[20] Bhogayata A C and Arora N K 2017 Fresh and strength properties of concrete reinforced with metallic plastic waste fibers. Construction and Building Materials 146: 455-463

[21] Khankhaje E, Hussin M W, Mirza J, Rafieizonooz M, Salim M R, Siong H C and Warid M N M 2016 On blended cement and geopolymer concretes containing palm oil fuel ash. Materials \& Design 89: 385-398

[22] Mohammadhosseini H, Yatim J M, Sam A R M and Awal A S M A 2017 Durability performance of green concrete composites containing waste carpet fibers and palm oil fuel ash. Journal of Cleaner Production 144: 448-458

[23] Ranjbar N, Behnia A, Alsubari B, Birgani P M and Jumaat M Z 2016 Durability and mechanical properties of self-compacting concrete incorporating palm oil fuel ash. Journal of Cleaner Production 112: 723-730

[24] Mohammadhosseini H and Yatim J M 2017 Microstructure and residual properties of green concrete composites incorporating waste carpet fibers and palm oil fuel ash at elevated temperatures. Journal of Cleaner Production 144: $8-21$

[25] Lim S K, Tan C S, Lim O Y and Lee Y L 2013 Fresh and hardened properties of lightweight foamed concrete with palm oil fuel ash as filler. Construction and Building Materials 46: 39-47

[26] Mohammadhosseini H, Awal A S M A and Sam A R M 2016 Mechanical and thermal properties of prepacked aggregate concrete incorporating palm oil fuel ash. Sādhanā 41(10): $1235-1244$

[27] Nia A A, Hedayatian M, Nili M and Sabet V A 2012 An experimental and numerical study on how steel and polypropylene fibers affect the impact resistance in fiberreinforced concrete. International Journal of Impact Engineering 46: 62-73.

[28] Afroughsabet V and Ozbakkaloglu T 2015 Mechanical and durability properties of high-strength concrete containing steel and polypropylene fibers. Construction and Building Materials 94: 73-82

[29] Mohammadhosseini H, Lim N H A S, Sam A R M and Samadi M 2017 Effects of elevated temperatures on residual properties of concrete reinforced with waste polypropylene carpet fibres. Arabian Journal for Science and Engineering 43(4): 1673-1686

[30] Mohammadhosseini H and Awal A S M A 2013 Physical and mechanical properties of concrete containing fibers from industrial carpet waste. International Journal of Research in Engineering and Technology 2(12): 464-468

[31] Zeyad A M, Johari M A M, Tayeh B A and Yusuf M O 2017 Pozzolanic reactivity of ultrafine palm oil fuel ash waste on strength and durability performances of high strength concrete. Journal of Cleaner Production 144: 511-522

[32] Chandara C, Azizli K A M, Ahmad Z A, Hashim S F S and Sakai E 2011 Analysis of mineralogical component of palm oil fuel ash with or without unburned carbon. Advanced Materials Research 173: 7-11

[33] Hsie M, Tu C and Song P S 2008 Mechanical properties of polypropylene hybrid fiber-reinforced concrete. Materials Science and Engineering A 494(1): 153-157

[34] Awal A S M A and Mohammadhosseini H 2016 Green concrete production incorporating waste carpet fiber and palm oil fuel ash. Journal of Cleaner Production 137: 157-166

[35] Neville A M and Brooks J J 2010 Concrete technology, 2nd ed. London: Pearson Education Limited

[36] Lim N H A S, Mohammadhosseini H, Tahir M M, Samadi M and Sam A R M 2018 Microstructure and strength properties of mortar containing waste ceramic nanoparticles. Arabian Journal for Science and Engineering 1-9, https://doi.org/10. 1007/s13369-018-3154-x 